\title{
THE EFFECT OF MELATONIN ON RAT PANCREATIC BETA CELLS IN VITRO
}

I. Kostoglou-Athanassiou, E. Papageorgiou, I.A. Vlachodimitris, C. Markopoulos, T. Karatzas, M. Koutsilieris

Department of Endocrinology, Red Cross Hospital, Athens, Greece

Department of Physiology, Medical School, University of Athens, Greece

Second Propedeutic Department of Surgery, Laiko General Hospital, Medical School, University of Athens, Greece

\section{OBJECTIVES}

\section{METHODS}

Melatonin is a hormone mainly synthesized and secreted by the pineal gland. It is involved in the orchestration of circadian rhythms its levels being elevated during the hours of darkness in the human. Melatonin may have other pleiotropic functions in the human organism. In particular, it may be involved in the regulation of glucose metabolism and the pathogenesis of diabetes.

The aim was to study the effect of melatonin on rat islet cells in vitro.
Rat pancreatic beta cells INS-1 were incubated for $48 \mathrm{~h}$ at $37^{\circ} \mathrm{C}$ in a humified atmosphere $5 \% \mathrm{CO}_{2}$ in the presence and absence of melatonin (SigmaAldrich). Melatonin was used at decreasing concentrations, the initial concentration being $200 \mathrm{nM}$, range $(200-6.25 \mathrm{nM})$. The proliferation of INS1 rat beta cells was assessed using the XTT cell proliferation assay (AppliChem). In order to determine the number of viable cells the cell proliferation kit XTT employs 2,3-Bis-(2-methoxy-4-nitro-5-sulfophenyl)-2Htetrazolium-5-carboxanilide salt (XTT). Only in living cells mitochondria are capable to reduce XTT to form an orange colored water soluble dye. Therefore, the concentration of the dye is proportional to the number of metabolically active cells.

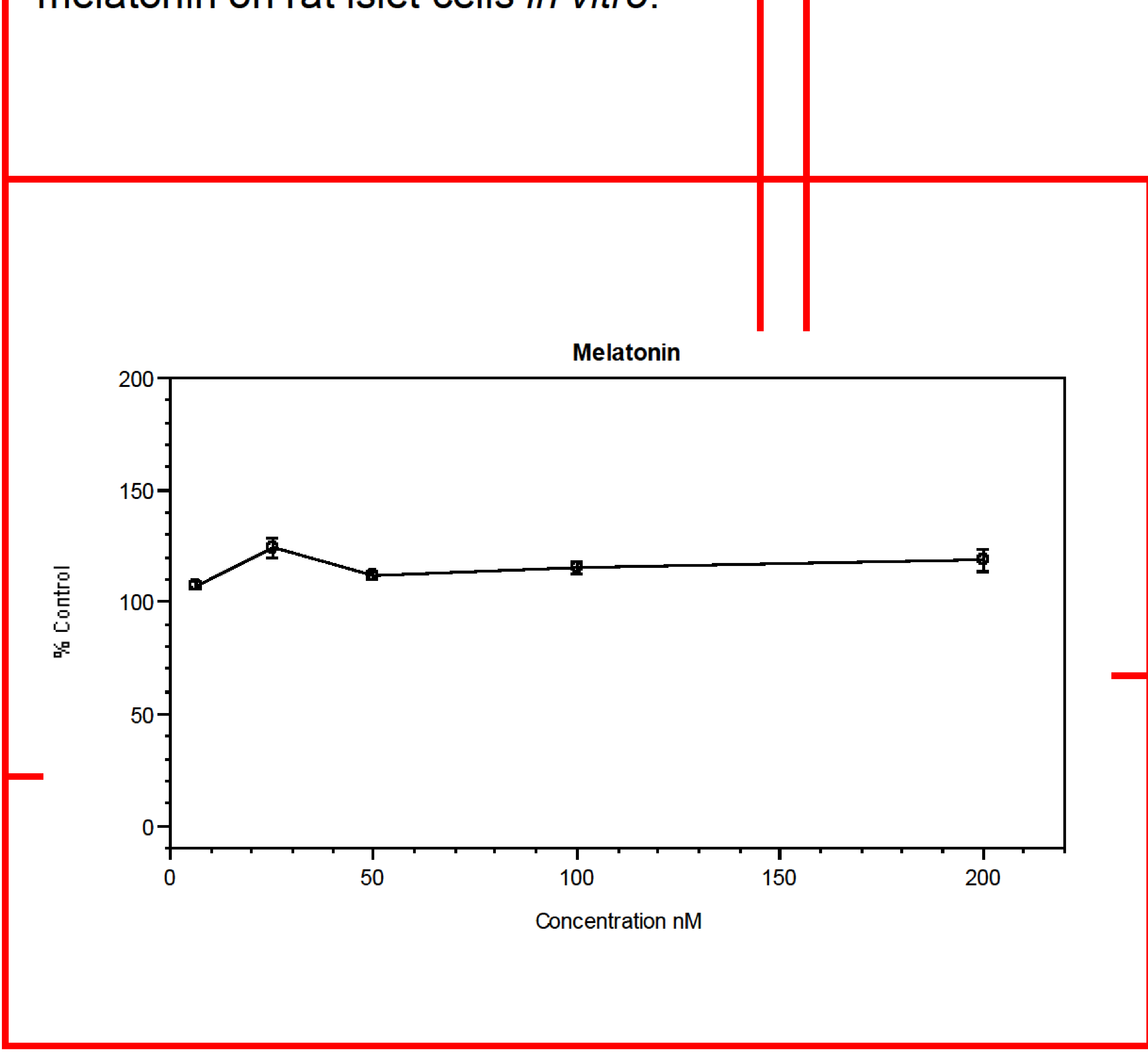

\section{CONCLUSIONS}

Melatonin, a pineal hormone involved in the regulation of circadian rhythms is now being investigated for its effects on glucose regulation. It has been found in human genome wide association studies that genetic variations in the melatonin receptor MT2 encoded by MTNR1B may coexist with diabetes. It was also suggested that genetic variations of MTNR1B may disorder b-cell function directly, via its effects on insulin secretion. In the present study melatonin was not found to affect islet cell mass in vitro. As it is speculated that melatonin and its receptors may be a new therapeutic avenue in diabetes further studies are needed to assess the effect of melatonin on insulin secretion.

\section{RESULTS}

Melatonin was not found to influence beta cells proliferation in vitro. 